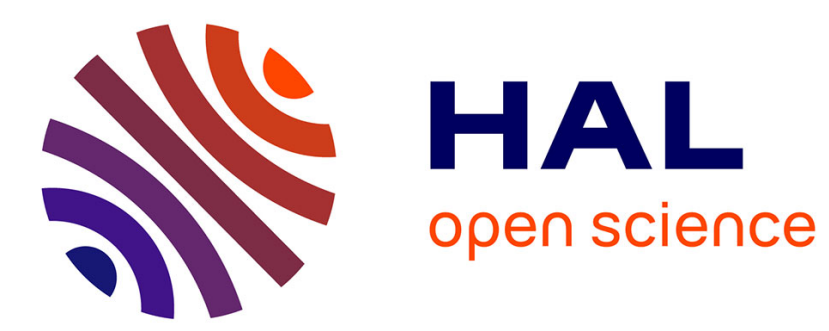

\title{
On the defence notion
}

Anne Bonfante, Jean-Yves Marion

\section{To cite this version:}

Anne Bonfante, Jean-Yves Marion. On the defence notion. Journal in Computer Virology, 2007, 3 (4), pp.247-251. 10.1007/s11416-007-0058-9 . hal-00184985

\section{HAL Id: hal-00184985 https://hal.science/hal-00184985}

Submitted on 4 Nov 2007

HAL is a multi-disciplinary open access archive for the deposit and dissemination of scientific research documents, whether they are published or not. The documents may come from teaching and research institutions in France or abroad, or from public or private research centers.
L'archive ouverte pluridisciplinaire HAL, est destinée au dépôt et à la diffusion de documents scientifiques de niveau recherche, publiés ou non, émanant des établissements d'enseignement et de recherche français ou étrangers, des laboratoires publics ou privés. 


\title{
On the defence notion ${ }^{\star}$
}

\author{
Anne Bonfante ${ }^{1}$ and Jean-Yves Marion ${ }^{1,2}$ \\ 1 Loria-INPL \\ Équipe Carte \\ anne.bonfante@libertysurf.fr, Jean-Yves.Marion@loria.fr \\ 2 École Nationale Supérieure \\ Mines de Nancy
}

\section{Computer virology and art of war}

"Trojan horses", "logic bombs", "armoured viruses" and "cryptovirology" are terms recalling war gears. In fact, concepts of attack and defence drive the world of computer virology, which looks like a war universe in an information society. This war has several shapes, from invasions of a network by worms, to military and industrial espionage...

For convenience, and because the term "virus" has a bigger impact from an epistemological point of view,

(the word "virus" was adopted after theoretical works of Cohen [1] and Adleman [2]) we will refer to "virus" or all the different kinds of computer infections. The reader may consult Filiol's books [3, 16] for further information about the definitions and classifications of malware.

We could think at first sight that questions about computer security, and particularly about fights against computer viruses, are just a matter of highly trained security computer officers, and that a victory just depends on scientific and technical knowledge. But sometimes algorithmic and programming are not enough to catch the whole picture. Indeed, the study of malware strategies shows that they are close to the battle of the Horacii against the Curiacii...

A different point of view could then bring to computer virology a new prospect. This study is a part of a general investigation, which tries to understand viral strategies in order to anticipate attacks and improve defences, and to define the philosophical and political issues. Reading famous strategists and philosophers could give precious information about conscious- or unconscious viral practices, explicit- and implicit behaviour of the malware's writers, whatever kind of attacks they launch. For this, a case study is a good way to make the connection between the technical or scientific profiles of a virus and the kind of strategy used (the meaning of the word "strategy" is here conveyed by political and war philosophies). The case of the Whale virus can be extended to the Bradley concept, its epistemological model, which is meaningful.

The question of War, as well as the best way to do it and the politicaland human issues related to it, is very old in the history of philosophy, as we

\footnotetext{
^ This work has been supported by project ARA Virus.
} 
can already find it in the Peloponnesian war 44, written by Thucydide, a Greek general and historian in 430 BC, or Plato's Republic [5] (420-340 BC). Philosophy of war has always been an active theme of philosophy and was the main issue for some authors like Machiavelli (1469-1527), who wrote the Art of war [6] in 1519 .

Are the writers of malware Machiavelli's readers? This question sounds like a joke, but is legitimate, as we shall see. Indeed, the more dangerous viruses are the ones which seem to apply principles and to use strategies of the art of war, like Machiavelli's, or from other war theorists like Clausewitz [7].

\section{Bradley defences}

The Whale virus challenged Scotland Yard for about two weeks during the 1990's [8]. This virus is a typical case study, because it has its own defensive weapons. From the Whale virus, a virus shape named Bradley was proposed by Filiol [9]. This shape, which could also be considered as an epistemological model, will guide us in our study on virus defences. Indeed, it uses very complex notions coming from mathematics and computer science in order to defend and attack.

Bradley protection systems are first used to prevent the detection of the viruses by an antivirus software, and then to bypass the defences of the host system, which is under attack. We will study the two most interesting types of defence: the armoured code aspect and the virus's one because they are typical and relevant. It is worth to notice that the furtive aspect was a Whale feature.

An armoured code consists in protecting a code from an analysis, which can be static by disassembling, or dynamic, by monitoring executions.

Protecting a code against static analysis is a scientific challenge. The paper of Barak \& al [10] on obfuscation is a good illustration of these difficulties. With the benefit of hindsight, all the protection methods used lean on the same approach. The code protection is performed by an obfuscator. In fact, the latter is a kind of compiler, which transforms a source programme $s$ into a scrambled programme $s^{\prime}$ in such a way that:

1. The scrambled programme $s^{\prime}$ computes the same thing as the source programme $s$. (in other words, there are semantically equivalent).

2. The runtime of the scrambled programme $s^{\prime}$ is close to the one of $s$. (that is up to a polynomial).

3. The programme $s^{\prime}$ is unreadable as well for a human analyst as for a deobfuscation programme.

The third point corresponds to the obfuscation clause, which turns out to be difficult to formalize. Obfuscation consists in rewriting the code in order to make it less understandable. Cryptography plays a crucial role in this task. The interested reader may consult the recent paper of Beaucamps and Filiol [12] about the practical obfuscation methods. Moreover, a virus may mutate when it duplicates with polymorphism or metamorphism techniques. 
An obfuscator protects a programme in a way that we could call passive, unlike furtivity techniques. It aims to camouflage a code in order to slow the analysis of its adversaries down. Advantage for the attacker with this method: the guarantee of immunity for a while, because the time spent to camouflage is ever shorter than the one spent by the adversary to detect it. Thus, the attacker protects itself against antivirus software, which, on the one hand search for a signature of a known malware. On the other hand, it protects itself against the work of analysts, which are trying to understand the meaning of its code. This method used by virus looks like both a camouflage and a shield, which are designed to resist an attack as long as possible. It appears then to be a method of passive defence.

A Bradley virus also combines an active defence method: "furtivity". It consists in deceiving a host system, by modifying, for example, system interruptions. In the case of Whale, techniques of furtivity allow to detect a debugger. The defence becomes active, because a virus can trigger an action off, if it is aware that some agent is trying to analyse it. Furtivity then allows the prevention of behavioural analysis techniques used by antivirus. Moreover, the resistance of a virus to such an analysis allows the collection of information about the defence methods of the host system. Consequently, we may suppose that this fact is a piece of its attack plan and the reasons why the virus was launched... We must then look at the reasons for which a virus like Bradley integrates so many defence techniques.

\section{Why does a virus defend itself?}

The part of the virus code which purpose is to infiltrate a system and to deceive the antivirus can be considered as both an offensive weapon (it enters a fortress) and a defensive weapon (camouflage). A particularity of Whale, as well as the Bradley concept, is that its code contains advanced defensive functionalities, which go beyond the traditional ones used to enter a system. If a virus was a mere offensive weapon, why allowing such defence mechanisms then?

If we send troops to attack a place, and whatever the issues are, it seems normal to arm them and to give them some means to protect themselves. Such defensive means are necessary in order to protect troops and avoid casualties. However, in the context of a conflict in the information society, what does the attacker try to protect?

If the only goal is to get some information back, the loss of a virus is a part of the operation. Why are viruses protected then? We think that the host systems should address those questions in order to prepare its defence.

This brings us to a first hypothesis. The attacker is a Machiavelli's reader without knowing it. Indeed, one of the fundamental principles of the art of war is that we must have both offensive and defensive weaponries. A good defence is meaningless if it is not armed: the only guarantee of autonomy and independence is the ability to be in a defensive position as well as in an offensive one if necessary. Computer security questions should then necessarily consider the 
possibility to prepare and use offensive methods. However, state legislations, like the French one, do not allow attacks and force security officers to set only defensive methods with no possibility of counter-attack. The efficiency of the defence is also related to the questioning about this ban on possessing and training with its own (offensive) weapons. Machiavelli's readers know how important it is to keep control over one's own weapons because it is a sine qua non condition for security and independence.

The second hypothesis is that a virus provides a defence because it has some hostile intentions. If there are as sophisticated high-level defence mechanisms as the ones mentioned above, it means that the virus was made for a very important purpose. We could use this criterion in order to set a typology of viral attacks: the more elaborated the defence is, the more important the objective is.

Lastly, the third hypothesis is that we should call security policy views into question. If a virus based on the Bradley concept integrates such elaborated sequences of defence, it is because it probably expects a serious counter-attack. The defences are thus stronger than what they claim or than they are known to be (but it is maybe a trick: fooling the adversary while looking more vulnerable than you are in reality.)

Other hypotheses are conceivable, and some show that 'viral war' takes sometimes paradoxical or new shapes we should study in order to anticipate the future.

\section{$4 \quad$ New time scales?}

Information technology war implies to have to reconsider the scales of the conflicts, particularly the time scale, but also the one of the space. The time necessary to decipher and analyse a virus (remember the two weeks which were necessary to analyse Whale!) is a "long" time. It means that it corresponds to a human time-scale. On the other hand, if we consider that a viral attack symbolically represents a hostile operation, the length of the attack is very short (between a second and a minute). There are at least two levels of analysis to bring out in order to understand the defence question:

- The human scale. The conception of dangerous viruses is a long process because they integrate a lot of mathematics and a big knowledge in computer science. It is hard to capture a virus and difficult to analyse it. This is the case of Whale.

- The computer scale. A virus is inside a system, and must fight against an anti-virus. The fight lasts a few seconds, or minutes, programme versus programme.

We could think at first sight that a viral attack is a completely new kind of war, since it takes place in an entirely different way compared to traditional war. Can we use the term of war again, since there is nothing in common between a few-second strike and a real battle in the field? 
A virus writer finds time to design a virus efficiently and cannot ignore that it will require a lot of time to decipher and analyse the virus, if it is captured. Therefore, this time was anticipated and should be considered as a genuine part of the attack. It can be used to create a diversion or to have more time (indeed, during the phase of analysis, the attacker can do something else). Then this type of virus corresponds more to a traditional war, and consequently sets conflicts back in a long time-scale and not in an instantaneous one. Isn't it the aim of the attacker? So don't we have to consider that a viral attack is just a weapon as another one, or just a part, of a global conflict? Such a viral attack is a way to set things back in a better-known field, which is more traditional, in a way more human: the field of men, logistics and "normal" time.

This shift of scale between viral attacks and traditional fights allows us to ask further questions. For example, look at the ratio between the 14 days of analysis, which is the time necessary to understand Whale, and 1 minute, which will be considered like a time-reference at the computer level. The ratio between these scales is around a million. The change of scale directly implies that when a viral attack is launched, it cannot be controlled at the human level anymore, because it is too fast. Admittedly, the use of a gun implies that its process is autonomous and does not depend on a human (when a gun is fired, the bullet is unavoidable... except in "Matrix"!). But in the case of a computer war, we should not consider a single virus, but a set of viruses against defences. Each of these agents communicates with the others, reacts to its environment and takes decisions, independently from any human interventions. Moreover, if the computer scale is very short, the conflict area could be the whole net [13]! This change of the scales maybe implies that we should change our classical concepts of war analysis, as we traditionally find them in books of great authors like Clausewitz [7].

\section{A central question: the losses}

Cyberwar implies to reconsider a crucial notion of every armed conflict: the one of the casualties. Indeed, why does someone program an armoured virus? What is the attacker's objective? What may he lose, and which losses does he want to avoid?

In the setting of traditional war with different armed forces, the question of the casualties is one of the most important to make strategic and tactical choices. This question is coupled with an obvious moral issue. This issue is represented by the assessment of the inherent ratio in any operation: the (human-, technicalor practical) cost of an action must be related to the interest or to the benefit of this action. So, this assumes the responsibility of the military leaders and of the governments, particularly a moral responsibility, since casualties should be avoided. Taking a risk should then be justified with respect to the current issue, especially when human lives are concerned. The moral responsibility is more difficult to take, but it just exists in the case of real wars, because we can always know the number of deaths, without always really understanding the benefit of 
an operation. Cyberwar changes traditional war categories, since the moral and the casualty question as well as the question of the just cause, do not come up anymore.

Inversely, the heroic figure or the heroic action supposes that the loss of a life is there for a great collective benefit. The greater the sacrifice of the hero is, the more he takes risks; the more conscious he is that he will not survive to his action, the more heroic he is. We can ask if hackers identify to the issues of the hero, as we already mentioned, by overcoming all difficulties and responding to all challenges. Indeed, the point for a hacker is here to accomplish a technical exploit giving him the feeling of being a hero, even if his actions are reprehensible. Recent movies show that clearly: it is the heroic figure of Neo in Matrix.

It seems to us that we should understand the specificity of modern wars with respect to how they consider casualties. In the case of a virus, the loss of the latter is somehow immaterial, maybe anticipated, or even programmed by its designer. It means, first, that we do not consider losses as real ones (like events to avoid), or at least that it is a part of the strategy, especially as we can always replace a virus: losses are duplicable because a virus can be duplicated.

Another characteristic of computer-war is that it does not lean on economical and industrial resources, which are decisive factors in the case of a "real" war, even if they are not the only ones. In the case of a viral war, the attacker's strength is not directly related to economical- or industrial resources, but to a scientific and technical knowledge, which then becomes a possible cause of war, or at least reasons for a competition.

When an attacker "loses" a virus, the latter can be analysed. From then on, we may reproduce quite easily its design. However, there are some interests in avoiding the loss of a viral weapon in order to protect knowledge, in terms of cryptography for example. The attacker, as a war leader or a strategist, measures the interest of an action and determines the risk he runs. One of the clearest specificities of a modern or post-modern conflict is that the technical questions aim more and more at replacing the question of force. Violent confrontation is shifted to technical considerations.

\section{Counter-attack and issues}

The viral defence system often allows the attacker to stay anonymous, which prevents possible counter-attacks. But this fact changes the concept of war because the enemy is not identified. What is peculiar to war is to have an enemy, a known opponent. Once the enemy remains anonymous, confrontation does not correspond to the representation of war, but more to guerrilla warfare: the enemy is not conventional and cannot be spotted.

Furthermore, if the attacker tries to hide his strategy as long as possible, it means that the host system itself can be protected. Indeed, a virus is able to delude a defence in such a way that it can be in position to observe tools used for defence: a virus is able to be behind the line, and so is able to list all defensive tools. Therefore, this means that the virus code has a mechanism the function 
of which is to detect the tools used by the defence in order to analyse intruders, viruses and so on.

We could conclude for the time being that the strategy used by the virus in this case is a prospective one. Detecting the defence tools has a meaning only if another attack is planned in the near future. Consequently, we should analyse the aims of the virus from a temporal point of view. A viral attack can be an initial assault before another one, so we should not simply consider what represents a given attack at a given time.

Lastly, the issues of computer virology are directly related to other domains where computer networks are used as tools to exchange information. It is a way to say that the field of viral war is also economic and financial, and that it implies political positions, in particular questions about individual rights. Economic issues are not always perceptible behind some behaviour, which may have some moral justifications: for example, it is the case of Sony rootkit [15]. The reason of the integration of computer virology was to protect author rights, and to protect the data contained in the disk. The reality was that this technology allowed to spy the user's data (it is of great interest from a commercial point of view...). The ambiguity is in the fact that Sony was perfectly able to justify this functionality, which is usually used by malware, in order to protect author rights. This worry is legitimate, but nothing proves that the real purpose was this one... So, computer virology is the place of different kinds of wars, but the hostility logic often remains the same.

\section{Evolutions and perspectives}

Viral defence, as a large part of computer security, depends on the results of theoretical computer science. For the record, there are Cohen's results on viral detection undecidability: it is not possible to construct perfect anti-virus software. Other results depend on conjectures of the algorithmic complexity theory (like if $\mathrm{P}=\mathrm{PSPACE}$, then practically all cryptographic codes will be broken). It is interesting to see once more that we face a scale problem. Indeed, conjectures related to the algorithmic complexity theory imply that a given problem is computable but the runtime is beyond belief and is greater than the age of the universe! Science acts as a guarantor for defence soundness. If a defence depends on the algorithmic complexity theory, so it must take into account the time scales that we have mentioned previously. A viral defence may be conceived to resist an analysis at a human scale, and from then on can be considered as immune with respect to the computer time scale (where the time scale is about a minute). On the other hand, during a computer attack, and at a computer time scale, this heavy defence slows the virus execution down. So, the issue is to choose the right weaponry according to the targets that are aimed. This subject was widely discussed in many strategy books, as Machiavelli did in his Art of war.

As we saw it above, viral war integrates the necessity of a prospective strategy: on the one hand, because it could use the information the virus found, 
pursuing the elaboration of its attack's tactics according to the environment it is located in. In this sense, a virus is a modern weapon since it is adaptable: there are interactions between a virus and its environment. There is an epistemological and scientific dimension as soon as we think about a viral attack as a deployment of a large number of autonomous and cooperative agents. This direction recalls analogies with biological immune systems [14]. Another possibility is to consider the agents of a network with divergent interests like in the algorithmic game theory. The game theory, which tries to predict behaviours of a population in a given environment, could then be used to analyse political and sociological behaviours of agents running viral attacks, and also of the users who are concerned by those attacks.

To come back to the question of the interaction of a virus in its environment, we can say it is inseparable from a forecast. That is that a virus adapts to its environment in order to pursue an attack, or to send information back with the view to make another attack. This temporal forecast, even if it is implicit, is the sign that a viral arm cannot be understood, or analysed, without thinking of the one who possesses it. The attacker's intention (or the intention of the ones who order this action) is revealed by the question, which seems harmless at first glance: what is the purpose of a weapon? If, to be specific, it can be used to make another attack, or just to pursue the current one: this attack is a step. It also means that it is necessary for the ones who are fighting against viral attacks, not only to view an attack here and now, but always to think about the intentions that could be implied. To give another conclusion to this discussion, we should analyse a viral attack by what it implicitly discloses: the virus's method for the attack indicates what its writer knows, or what he thinks he knows about the target he aims. Anybody thinking he is a potential target should integrate into its security policy what he wants to show to the others, in such a way that he directs the kind of attack he can be the target of. The issue at stake here is to apply the good old strategy: a false lure, a false target, or a noticeable weakness, which transforms stratagems into an art of playing with representations and to trick enemies. We must always come back to this Machiavelli's principle: "Never believe that the enemy doesn't know what he does", always assume that you have to deal with a smart-, surely crafty enemy, whose intentions are not always visible. So, the security of a target should not only stem from the strength of a defence: the attackers will always succeed to penetrate by a way or another. We should also know how to use trickery, how to play with psychological effects and make our opponent believe that defences are different from what they really are...

\section{Acknowledgement}

We would like to thank first lieutenant de Marqueissac for her valuable help in improving the correctness of our English. 


\section{References}

1. F. Cohen. Computer Viruses. PhD thesis, University of Southern California, January 1986.

2. L. Adleman. An abstract theory of computer viruses. In Crypto' 88 - Advances in Cryptology, Lecture Notes in Computer Science 403, 1988.

3. E. Filiol. Computer viruses: from theory to applications, IRIS International Serie, Springer, 2004.

4. Thucydide. The Peloponnesian war.

5. Platon. The Republic.

6. N. Machiavel. The art of war.

7. C. Clausewitz. On war.

8. E. Filiol. Whale : le virus se rebiffe. Journal de la sécurité informatique MISC 19, Mai 2005.

9. E. Filiol. Strong Cryptography Armoured Computer Viruses Forbidding Code Analysis: the Bradley Virus, In Proceedings of the 14th EICAR Conference, pp 216-227, Malta, 2005.

10. B. Barak, O. Goldreich, R. Impagliazzo, S. Rudich, A. Sahay, S. Vadhan and K. Yang, On the (Im)possibility of Obfuscating Programs. Lecture Notes in Computer Science, 2139, Crypto, 2001.

11. Cryptographie malicieuse. Journal de la sécurité informatique MISC 20, juillet 2005.

12. P. Beaucamps and E. Filiol. On the possibility of practically obfuscating programs: towards a unified perspective of code protection. TCV 2006 Special Issue, Journal of computer virology, 3 (1), pp. 3-21, 2007.

13. I. Balepin. Superworms and Cryptovirology: a Deadly Combination. http://www .

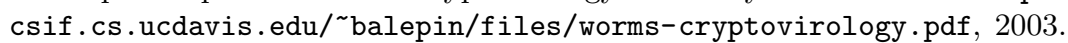

14. Editorial, Making connections. Nature Immunology 3-10, Octobre 2002.

15. Sony Rootkit Case: http://www.sysinternals.com/blog/2005/10/ sony-rootkits-and-digital-rights.html

16. E. Filiol, Techniques virales avancées, Collection IRIS, Springer, 2007 (an English translation is due on december 2007). 